\title{
The Association of Type and Number of Chronic Diseases with Breast, Cervical, and Colorectal Cancer Screening
}

Betty Y. Liu, MD, MPH, Jean O'Malley, MPH, Motomi Mori, PhD, Lyle J. Fagnan, MD, David Lieberman, MD, Cynthia D. Morris, PhD, MPH, David I. Buckley, MD, MPH, John D. Heintzman, MD, and Patricia A. Carney, PhD

Purpose: The purpose of this study was to examine associations between the number and types of patients' chronic diseases and being up to date for breast, cervical, and colorectal cancer screening.

Methods: Data were abstracted from medical charts at 4 primary care clinics located in 2 rural Oregon communities. Eligibility criteria included being at least 55 years old and having at least 1 clinic visit in the past 2 years.

Results: Of 3433 patients included, 503 (15\%) had no chronic illness, $646(19 \%)$ had 1, $786(23 \%)$ had 2 , and 1498 (44\%) had $\geq 3$ chronic conditions. Women with asthma/chronic lung disease and with cardiovascular disease were less likely to be up o date for mammography screening (odds ratio [0R], 0.59; 95\% confidence interval $[\mathrm{CI}], 0.43-0.80$ ), and those with chronic digestive disorders were more likely to be up to date for mammography $(0 R, 1.31 ; 95 \%$ CI, 1.03-1.66) compared with those without chronic conditions. Women with arthritis, diabetes mellitus, and hypertension were less likely to be up to date for cervical cancer screening (OR, 0.38; 95\% CI, 0.21-0.68) compared with those without chronic conditions. Men with cardiovascular disease were less likely to be up to date for colorectal cancer screening (adjusted OR, 0.59; 95\% CI, $0.44-$ $0.80)$, and women with depression were less likely to be up to date $(\mathrm{OR}, 0.71 ; 95 \% \mathrm{CI}, 0.56-0.91)$ compared with men and women without chronic conditions.

Conclusion: Specific chronic conditions were found to be associated with up-to-date status for cancer screening. This finding may help practices to identify patients who need to receive cancer screening. (J Am Board Fam Med 2014;27:669-681.)

Keywords: Cancer Screening, Chronic Disease, Rural Health

Although the benefits of breast, cervical, and colorectal cancer screening have been widely established, ${ }^{1-3}$ utilization of screening continues to be suboptimal. ${ }^{4-9}$ Data from the National Health In-

This article was externally peer reviewed.

Submitted 8 January 2014; revised 13 May 2014; accepted 19 May 2014.

From the Department of Family and Preventive Medicine, University of Utah, Salt Lake City (BYL); the Department of Public Health and Preventive Medicine, Division of Biostatistics (JO, MM), the Department of Family Medicine (LJF, DIB, JDH, PAC), the Department of Internal Medicine, Division of Gastroenterology (CDM), the Department of Medical Informatics and Clinical Epidemiology (CDM, DIB), and the Department of Public Health and Preventive Medicine (DIB, PAC) Oregon Health \& Science University, Portland.

Funding: This work was supported the American Cancer Society (RSGI-07-1661-01CPHPS 01), the Research Program at Oregon Health \& Science University's Department terview Survey showed that breast and cervical cancer screening steadily declined between 2000 and 2010. ${ }^{10}$ Colorectal cancer screening increased slightly (from $43.1 \%$ to $50.2 \%$ ) between 2005 and 2008, primarily because of the rise in colonoscopies. ${ }^{9}$ Along with a decline or only a slight increase in screening rates,

of Family Medicine, and the Oregon Clinical and Translational Research Institute (OCTRI); grant no. TL1 RR024159 from the National Center for Research Resources (NCRR), a component of the National Institutes of Health (NIH); and the Biostatistics Shared Resource of the Knight Cancer Institute (2P30 CA069533-14).

Conflict of interest: none declared.

Corresponding author: Patricia A. Carney, $\mathrm{PhD}$, Departments of Family Medicine and Public Health and Preventive Medicine, MC-FM, Oregon Health \& Science University, 3181 SW Sam Jackson Park Rd, Portland, OR 97239-3098 (E-mail: carneyp@ohsu.edu). 
health disparities exist among different populations that require attention, such as rural residents. ${ }^{1-16}$ Distance from metropolitan areas, underserved race or ethnicity, and other socioeconomic factors all influence receipt of cancer screening. ${ }^{8,15,17}$ Even when access is not a problem, lack of health maintenance visits and lack of physician recommendations are barriers to cancer screening tests. ${ }^{18}$

The presence of one or more chronic diseases may make receipt of cancer screening even more complex. Some chronic illnesses, such as diabetes, serve as independent risk factors for certain cancers $^{19-21}$ and may be associated with cancer mortality, ${ }^{22}$ while also serving as barriers to receipt of screening. ${ }^{23-25}$ Conversely, other studies found the presence of chronic diseases is associated with better cancer screening utilization. Patients with hypertension have been reported to have more breast exams, Papanicolaou tests, and fecal occult blood tests compared with those without it, and mammography, breast exams, and Papanicolaou tests have been found to be higher in women with $\geq 3$ chronic conditions. ${ }^{26-29}$

How chronic diseases affect screening of breast, cervical, and colorectal cancers remains controversial. The conflicting findings reported in the literature cited above may be because of the different settings, time periods during which recommendations for cancer screening changed, and geographic locations time periods being studied. Managing chronic illnesses and providing cancer screening may compete for clinicians' limited time in busy primary care settings, ${ }^{30,31}$ whereas more frequent clinic visits for chronic conditions may present opportunities for cancer screening. Work is still needed to achieve the Healthy People 2020 goals of colorectal, breast, and cervical cancer screening rates of $70.5 \%, 81.1 \%$, and $93 \%$, respectively. ${ }^{32}$ Our study focused on several tests for breast, cervical, and colorectal cancer screening within a single time period and geographic location-rural understudied primary care practices—and specifically examined the impact of 16 different chronic conditions on being up to date for cancer screening while adjusting for potential confounders. We specifically tested the hypothesis that there is an inverse relationship between the number of comorbid conditions that patients had and the likelihood that they would be up to date for any cancer screening tests.

\section{Methods}

\section{Study Design, Setting, and Population}

We performed a medical record review with the Oregon Rural Practice-based Research Network. Study design and data collection were detailed in a recent publication. ${ }^{15}$ Briefly, data were collected from medical charts at 4 primary care clinics located in 2 rural Oregon communities. Eligibility criteria for patients included being at least 55 years old (to ensure they met screening criteria); having at least 1 clinic visit in the past 2 years; and having medical records extending up to 10 years before the date of the review. All study activities were approved by the institutional review board of Oregon Health \& Science University and conducted under a Health Insurance Portability and Accountability Act waiver for collection of personal health information without consent.

\section{Data Collection/Medical Record Review}

Medical records were reviewed between October 2008 and August 2009. We collected dates when eligible patients received colorectal, breast, and cervical cancer screening for up to 10 years. Colorectal cancer screening tests included fecal occult blood tests, colonoscopy, flexible sigmoidoscopy, and double-contrast barium enema; breast cancer screening included mammography; and cervical cancer screening included the Papanicolaou test (Papanicolaou).

We collected patients' demographic information; health insurance status; personal and family history of cancers and type of cancer; prior abnormal screening test results for colorectal, breast, or cervical cancers; numbers and types of chronic conditions from problem lists or patient notes; years of care received by clinic; total number of clinic visits; and type of clinic visit (health maintenance vs acute care or chronic care). The 16 chronic conditions were collapsed into the following 10 categories for analysis: (1) arthritis/musculoskeletal disease/degenerative joint disease, (2) asthma/emphysema/ chronic obstructive pulmonary disease/chronic lung disease, (3) cardiovascular disease, (4) hypertension, (5) chronic digestive disease, (6) chronic pain, (7) low-back pain, (8) diabetes mellitus, (9) depression/anxiety, and (10) substance abuse. The grouping decisions were made with input from the physician investigators on our team (L.F., D.B., and J.H.) and reflected common management ap- 
proaches. We grouped these diseases into a discrete variable. Unlike the Charlson index, ${ }^{33}$ our variable for number of chronic conditions is not an aggregated predictor of mortality risk from chronic conditions.

For up-to-date status of cancer screenings, we used the US Preventive Services Task Force guidelines ${ }^{34-36}$ in effect during the chart review period (2008/2009). Subjects were considered up to date if the most recent screening mammography, Papanicolaou, or colorectal cancer screening test was recorded to have been within the appropriate screening time interval for their risk status (eg, family history in a first-degree relative).

\section{Data Exclusions and Statistical Analysis}

The initial data abstraction included 3593 patients, of whom we excluded 160, for a total of 3433 . We excluded patients whose age was missing $(n=5)$ and those with any personal history of breast, cervical, ovarian, or colorectal cancer $(n=155)$. In our analyses of breast cancer screening, we also excluded women with a recent history of an abnormal mammogram because we could not be certain whether a patient had returned for screening or diagnostic mammography. Similarly, for analyses of cervical cancer screening, we excluded women with recent abnormal Papanicolaou tests because the follow-up could include other Papanicolaou, invasive sampling, or human papillomavirus testing, and there is uncertainty of a diagnosis of cancer. We excluded patients with a history of abnormal colorectal screening examination because these circumstances could also indicate an impending cancer diagnosis, making these patients more similar to those we excluded because of a personal history of cancer. For colorectal cancer screening, we did not exclude those from whom a polyp had been removed because return for surveillance or screening is clearer than it is for mammography and the time interval for return is longer than it is for abnormal mammography and Papanicolaou tests.

We calculated $\kappa$ coefficients for agreement between the 2 medical record reviewers for all abstracted variables. We excluded 2 chronic conditions with $\kappa$ values ${ }^{37,38}<0.4$, substance abuse, and chronic pain; agreement for other chronic diseases ranged from 0.5 and 0.9. body mass index (BMI) was divided into 4 categories according to World Health Organization guidelines: $<25 \mathrm{~kg} / \mathrm{m}^{2}$, be- tween 25 and $30 \mathrm{~kg} / \mathrm{m}^{2}, \geq 30 \mathrm{~kg} / \mathrm{m}^{2}$, and not noted. The underweight category of $<18.5 \mathrm{~kg} / \mathrm{m}^{2}$ had only 30 individuals, considered too small for accurate estimation in the regression model. A sensitivity analysis using regressions that included and excluded those 30 individuals did not alter the odd ratios or $P$ values of any of the variables; thus, we collapsed the underweight individuals into the category of $<25 \mathrm{~kg} / \mathrm{m}^{2}$ to preserve the overall sample size. We divided age into 4 categories according to its distribution: 50 to 59,60 to 64,65 to 75 , and $>75$ years. For cervical cancer screening, the age categories were limited to 50 to 59 and 60 to 64 because the guidelines do not include recommendations for women older than 65 . We categorized the number of clinic visits within the audit period and the total length of patient contact with a clinic. Visit counts were divided into 4 categories: $<5$ visits, 5 to 10 visits, 11 to 20 visits, and $>20$ visits. Patient's overall length of contact with a clinic was divided into 5 categories: $<6$ months, 6 months to $<1$ year, 1 year to $<2$ years, 2 years to $<5$ years, $\geq 5$ years.

We used the $\chi^{2}$ test to examine possible associations between various patient characteristics and the number of chronic conditions present. The assessed characteristics included demographics, health behaviors, clinic utilization, presence of specific chronic diseases, and up-to-date status for cancer screening. We then used multivariate mixed effects logistic regression models to assess the association of both the total number of chronic conditions and specific chronic diseases with up-to-date cancer screening status. These models included clinic as a random effect and adjusted for a standard set of potential confounders that included age, marital status, ethnicity, BMI classification, occupation, insurance status, alcohol history, smoking history, length of contact with clinic, number and type of clinic visits, and other chronic diseases. Because screening practices can vary by clinician within each clinical practice, we treated the clinics as a random effect in our models. We used a stepwise selection procedure to develop a logistic regression model for each screening status outcome. Colorectal cancer modeling was stratified by sex. We also explored possible interactions between insurance type, ethnicity, number of visits, and length of contact and each chronic disease, but no significant effect modifications were found. We used STATA statistical soft- 
ware version 11.2 (StataCorp., College Station, TX) for these analyses.

\section{Results}

\section{Study Population}

We identified 503 patients (15\%) who had no chronic illness, 646 (19\%) with 1, 786 (23\%) with 2, and 1498 (44\%) with $\geq 3$ conditions (Table 1). The mean and median numbers of chronic conditions were 2.44 and 2, respectively (range, $0-10$ ) (data not shown). Of patients $49 \%$ were up to date for breast cancer screening, 52\% for cervical cancer screening, and $37 \%$ for colorectal cancer screening (using any screening test). The number of chronic disease conditions was significantly different for many patient characteristics, including community of residence, patient age, race and ethnicity, marital status, occupation, insurance coverage, BMI, other health habits such as smoking history and alcohol use, and types of chronic illnesses (Table 1). The mean length of contact with a clinic and the mean number of clinic visits both increased with increasing number of conditions.

The most common chronic disease was hypertension, which was present in $48 \%$ of all patients and $27 \%$ of patients with only one chronic disease (Table 1). Of those patients with 2 conditions, many had arthritis or other joint diseases (26\%) and hypertension $(53 \%)$. Of those patients with $\geq 3$ conditions, most had hypertension (71\%) or arthritis/joint diseases (59\%), and many had cardiovascular disease $(40 \%)$, chronic digestive disorders (40\%), depression (45\%), and/or low-back pain (42\%).

\section{Breast Cancer Screening}

Of the 1870 women identified for the study, 1859 were included in the analysis of breast cancer screening status. Six women were excluded because they had an abnormal mammogram within 2 years of the chart review, 4 women had bilateral mastectomies, and 1 woman was transgender. The unadjusted odds of being up to date for mammography increased with one or more chronic diseases (Table 2). Analyses that adjusted only for the total number of visits indicated that women with $\geq 3$ chronic conditions were less likely to be up to date compared with those with no chronic conditions (odds ratio $[\mathrm{OR}], 0.62 ; 95 \%$ confidence interval $[\mathrm{CI}]$, $0.45-0.87$ ) (Table 2). In the fully adjusted model, the negative association of $\geq 3$ chronic conditions with mammography decreased in magnitude and was not statistically significant. Because having a digestive disorder was consistently associated with being up to date for mammography screening (Table 3), we also tested the association in women without chronic digestive disorders. Excluding patients with digestive disorders reduced the odds of being up to date for mammography for women with 2 chronic conditions and women with $\geq 3$ conditions (Table 2).

Logistic regression modeling found that asthma/ chronic obstructive pulmonary disease/chronic lung disease, cardiovascular disease, and chronic digestive disorder were all significantly associated breast cancer screening status (Table 3). In our final adjusted models, women with asthma/chronic lung disease (OR, 0.59; 95\% CI, 0.43-0.80) and with cardiovascular disease (OR, 0.71; 95\% CI, 0.54-0.94) were less likely to be up to date for mammography screening, and those with chronic digestive disorders were more likely to be up to date (OR, 1.31; 95\% CI, 1.03-1.66).

\section{Cervical Cancer Screening}

Of the 1870 women in the study, 1103 were younger than age 65 . Of these women, 373 were excluded from the analysis because of a history of hysterectomy $(\mathrm{n}=350)$ or abnormal cervical cancer screenings within the past 2 years $(\mathrm{n}=23)$, leaving 740 women in the analysis. The unadjusted odds of being up to date for cervical cancer screening were not significantly different according to the number of chronic conditions (Table 4). When adjusted for the number of clinic visits alone or for numerous patient characteristics, women with 2 chronic conditions (OR, 0.55; 95\% CI, 0.31-0.95) or $\geq 3$ chronic conditions (OR, 0.38 ; 95\% CI, 0.21 $0.68)$ were less likely to be up to date for cervical cancer screening than women with no chronic conditions. When the analysis was limited to women with no digestive disorders, the negative association of having 2 chronic conditions with cervical cancer screening status was not statistically significant.

In unadjusted models, hypertension was the only chronic disease significantly associated with cervical cancer screening status. Three chronic diseases-arthritis/degenerative joint disease, diabetes mellitus, and hypertension-were significantly associated with lower odds of being up to date for cervical cancer screening in analyses that adjusted 
Table 1. Patient Characteristics by Number of Chronic Disease Conditions

\begin{tabular}{|c|c|c|c|c|c|}
\hline Characteristics & $\begin{array}{c}\text { No Conditions } \\
\mathrm{n}(\%)\end{array}$ & $\begin{array}{c}1 \text { Condition } \\
\mathrm{n}(\%)\end{array}$ & $\begin{array}{l}2 \text { Conditions } \\
\mathrm{n}(\%)\end{array}$ & $\begin{array}{c}\geq 3 \text { Conditions } \\
\mathrm{n}(\%)\end{array}$ & $P$ Value \\
\hline Total & $503(15)$ & $646(19)$ & $786(23)$ & $1498(44)$ & \\
\hline \multicolumn{6}{|l|}{ Community } \\
\hline A & $121(24)$ & $182(28)$ & $302(38)$ & $624(42)$ & \multirow[t]{2}{*}{$<.001$} \\
\hline B & $382(76)$ & $464(72)$ & $484(62)$ & $874(58)$ & \\
\hline \multicolumn{6}{|l|}{ Sex } \\
\hline Female & $268(53)$ & $346(54)$ & $419(53)$ & $837(56)$ & \multirow[t]{2}{*}{.55} \\
\hline Male & $235(47)$ & $300(46)$ & $367(47)$ & $661(44)$ & \\
\hline \multicolumn{6}{|l|}{ Age, years } \\
\hline $50-59$ & $291(58)$ & $287(44)$ & $303(39)$ & $465(31)$ & \multirow[t]{4}{*}{$<.001$} \\
\hline $60-64$ & $94(19)$ & $150(23)$ & $159(20)$ & $321(21)$ & \\
\hline $65-75$ & $85(17)$ & $138(21)$ & $201(26)$ & $382(26)$ & \\
\hline$>75$ & $33(7)$ & $71(11)$ & $123(16)$ & $330(22)$ & \\
\hline \multicolumn{6}{|l|}{ Ethnicity } \\
\hline Hispanic & $42(8)$ & $92(14)$ & $109(14)$ & $180(12)$ & \multirow[t]{3}{*}{.02} \\
\hline Non-Hispanic & $154(31)$ & $199(31)$ & $224(29)$ & $491(33)$ & \\
\hline Unspecified & $307(61)$ & $355(55)$ & $453(58)$ & $827(55)$ & \\
\hline \multicolumn{6}{|l|}{ Race } \\
\hline White & $228(45)$ & $332(51)$ & $444(56)$ & $1016(68)$ & \multirow[t]{3}{*}{$<.001$} \\
\hline Other & $14(3)$ & $21(3)$ & $25(3)$ & $40(3)$ & \\
\hline Unspecified & $261(52)$ & $293(45)$ & $317(40)$ & $442(30)$ & \\
\hline \multicolumn{6}{|l|}{ Marital status } \\
\hline Partnered & $336(67)$ & $423(65)$ & $490(62)$ & $890(59)$ & \multirow[t]{3}{*}{$<.001$} \\
\hline Not partnered & $99(20)$ & $150(23)$ & $223(28)$ & $510(34)$ & \\
\hline Unknown & $68(14)$ & $73(11)$ & $73(9)$ & $98(7)$ & \\
\hline \multicolumn{6}{|l|}{ Occupation } \\
\hline Employed & $288(57)$ & $343(53)$ & $342(44)$ & $456(30)$ & \multirow[t]{4}{*}{$<.001$} \\
\hline Unemployed/disabled & $21(4)$ & $48(7)$ & $75(10)$ & $256(17)$ & \\
\hline Retired & $104(21)$ & $144(22)$ & $237(30)$ & $566(38)$ & \\
\hline Unknown & $90(18)$ & $111(17)$ & $132(17)$ & $220(15)$ & \\
\hline \multicolumn{6}{|l|}{ Insurance } \\
\hline Private & $317(63)$ & $363(56)$ & $404(51)$ & $756(50)$ & \multirow[t]{5}{*}{$<.001$} \\
\hline Medicare/Private & $33(7)$ & $93(14)$ & $136(17)$ & $311(21)$ & \\
\hline Medicaid/Medicare & $15(3)$ & $19(3)$ & $34(4)$ & $122(8)$ & \\
\hline Uninsured & $34(7)$ & $48(7)$ & $81(10)$ & $120(8)$ & \\
\hline Unknown & $104(21)$ & $123(19)$ & $131(17)$ & $189(13)$ & \\
\hline \multicolumn{6}{|l|}{ Body mass index, $\mathrm{kg} / \mathrm{m}^{2}$} \\
\hline$<25$ & $151(30)$ & $133(21)$ & $126(16)$ & $215(14)$ & \multirow[t]{4}{*}{$<.001$} \\
\hline $25-29$ & $138(27)$ & $176(27)$ & $211(27)$ & $348(23)$ & \\
\hline$\geq 30$ & $65(13)$ & $165(26)$ & $237(30)$ & $522(35)$ & \\
\hline Unknown & $149(30)$ & $172(27)$ & $212(27)$ & $413(28)$ & \\
\hline \multicolumn{6}{|l|}{ Smoking history } \\
\hline Nonsmoker & $350(70)$ & $407(63)$ & $451(57)$ & $689(46)$ & \multirow[t]{4}{*}{$<.001$} \\
\hline Former smoker & $82(16)$ & $143(22)$ & $187(24)$ & $454(30)$ & \\
\hline Current smoker & $20(4)$ & $50(8)$ & $105(13)$ & $305(20)$ & \\
\hline Unknown & $51(10)$ & $46(7)$ & $43(5)$ & $50(3)$ & \\
\hline \multicolumn{6}{|l|}{ Alcohol use } \\
\hline Nonuser & $170(34)$ & $256(40)$ & $331(42)$ & $697(47)$ & $<.001$ \\
\hline Former user & $20(4)$ & $32(5)$ & $58(7)$ & $136(9)$ & \\
\hline Current user & $245(49)$ & $293(45)$ & $329(42)$ & $570(38)$ & \\
\hline Unknown & $68(14)$ & $65(10)$ & $68(9)$ & $95(6)$ & \\
\hline
\end{tabular}

Continued 
Table 1. Continued

\begin{tabular}{|c|c|c|c|c|c|}
\hline Characteristics & $\begin{array}{l}\text { No Conditions } \\
\mathrm{n}(\%)\end{array}$ & $\begin{array}{l}1 \text { Condition } \\
\mathrm{n}(\%)\end{array}$ & $\begin{array}{l}2 \text { Conditions } \\
\mathrm{n}(\%)\end{array}$ & $\begin{array}{l}\geq 3 \text { Conditions } \\
\mathrm{n}(\%)\end{array}$ & $P$ Value \\
\hline \multicolumn{6}{|l|}{$\begin{array}{l}\text { Mean length of contact with clinic, } \\
\text { years (SD) }\end{array}$} \\
\hline $\begin{array}{l}\text { Health care visits in past } 5 \text { years } \\
\text { mean (SD) }\end{array}$ & $5.2(4.9)$ & $8.4(7.0)$ & $12.5(13.7)$ & $24.0(24.3)$ & $<.001$ \\
\hline \multicolumn{6}{|l|}{ Chronic diseases } \\
\hline Arthritis/MS/joint disease & $0(0)$ & $76(12)$ & $207(26)$ & $884(59)$ & $<.001$ \\
\hline No disease & $503(100)$ & $570(88)$ & $579(74)$ & $614(41)$ & \\
\hline $\begin{array}{l}\text { Asthma/COPD/chronic } \\
\text { respiratory }\end{array}$ & $0(0)$ & $22(3)$ & $58(7)$ & $353(24)$ & $<.001$ \\
\hline No disease & $503(100)$ & $624(97)$ & $728(93)$ & $1145(76)$ & \\
\hline Cardiovascular disease & $0(0)$ & $49(8)$ & $118(15)$ & $598(40)$ & $<.001$ \\
\hline No disease & $503(100)$ & $597(92)$ & $668(85)$ & $900(60)$ & \\
\hline Chronic digestive disorders & $0(0)$ & $67(10)$ & $153(19)$ & $596(40)$ & $<.001$ \\
\hline No disease & $503(100)$ & $579(90)$ & $633(81)$ & $902(60)$ & \\
\hline Diabetes mellitus type 1 or 2 & $0(0)$ & $44(7)$ & $116(15)$ & $436(29)$ & $<.001$ \\
\hline No disease & $503(100)$ & $602(93)$ & $670(85)$ & $1062(71)$ & \\
\hline Depression/anxiety & $0(0)$ & $81(13)$ & $162(21)$ & $673(45)$ & $<.001$ \\
\hline No disease & $503(100)$ & $565(87)$ & $624(79)$ & $825(55)$ & \\
\hline Hypertension & $0(0)$ & $173(27)$ & $413(53)$ & $1068(71)$ & $<.001$ \\
\hline No disease & $503(100)$ & $473(73)$ & $373(47)$ & $430(29)$ & \\
\hline Low back pain & $0(0)$ & $58(9)$ & $129(16)$ & $626(42)$ & $<.001$ \\
\hline No disease & $503(100)$ & $588(91)$ & $657(84)$ & $872(58)$ & \\
\hline \multicolumn{6}{|l|}{ Up-to-date status } \\
\hline \multicolumn{6}{|l|}{ Colorectal cancer in men } \\
\hline Up to date & $77(33)$ & $103(34)$ & $146(40)$ & $271(41)$ & .06 \\
\hline Not up to date & $158(67)$ & $197(66)$ & $221(60)$ & $390(59)$ & \\
\hline \multicolumn{6}{|l|}{ Colorectal cancer in women } \\
\hline Up to date & $96(36)$ & $128(37)$ & $132(32)$ & $331(40)$ & .05 \\
\hline Not up to date & $172(64)$ & $218(63)$ & $287(69)$ & $506(60)$ & \\
\hline \multicolumn{6}{|l|}{ Breast cancer } \\
\hline Up to date & $125(47)$ & $176(51)$ & $199(48)$ & $420(51)$ & .60 \\
\hline Not up to date & $142(53)$ & $170(49)$ & $217(52)$ & $410(49)$ & \\
\hline \multicolumn{6}{|l|}{ Cervical cancer } \\
\hline Up to date & $87(53)$ & $90(54)$ & $77(50)$ & $130(51)$ & .82 \\
\hline Not up to date & $76(47)$ & $76(46)$ & $78(50)$ & $126(49)$ & \\
\hline
\end{tabular}

COPD, chronic obstructive pulmonary disease; MS, multiple sclerosis.

for marital status, BMI, number of visits, and other chronic diseases (Table 5).

\section{Colorectal Cancer Screening}

In unadjusted analyses, men and women with $\geq 3$ chronic diseases were significantly more likely to be up to date for colorectal cancer screening than those with no chronic conditions (men: OR, 1.44; 95\% CI, 1.03-2.02; women: OR, 1.37; 95\% CI, 1.02-1.84) (Table 6). However, when adjusted for the number of visits in the past 5 years, these patients were significantly less likely to be up to date (men: OR, 0.61; 95\% CI, 0.41-0.91; women: OR, $0.62 ; 95 \%$ CI, 0.44-0.89). When fully adjusted for covariates, the negative association of colorectal screening with the number of chronic conditions lost statistical significance; however, when patients with chronic digestive disorders were excluded from the analysis, the negative association with $\geq 3$ chronic conditions was statistically significant (Table 6).

Male patients with cardiovascular disease were significantly less likely to be up to date for colorectal cancer screening (adjusted OR, 0.59; 95\% CI, 0.44-0.80), whereas men with chronic digestive 
Table 2. Unadjusted and Adjusted Odds Ratios for Up-to-Date Breast Cancer Screening Status According to US Preventive Services Task Force Guidelines by Number of Chronic Conditions

\begin{tabular}{|c|c|c|c|c|c|c|c|c|}
\hline \multirow[b]{3}{*}{ Conditions (n) } & \multicolumn{8}{|c|}{ Up-to-Date Mammography Status } \\
\hline & \multicolumn{6}{|c|}{ All Chronic Conditions } & \multicolumn{2}{|c|}{$\begin{array}{c}\text { Excluding Patients with } \\
\text { Digestive Disorders }\end{array}$} \\
\hline & $\begin{array}{l}\text { Bivariate OR } \\
(95 \% \mathrm{CI})\end{array}$ & $\begin{array}{c}P \\
\text { Value }\end{array}$ & $\begin{array}{l}\text { Model 1,* } \\
\text { Adjusted OR } \\
\text { (95\% CI) }\end{array}$ & $\begin{array}{c}P \\
\text { Value }\end{array}$ & $\begin{array}{l}\text { Model 2, } \\
\text { Adjusted }\end{array}$ & $\begin{array}{c}P \\
\text { Value }\end{array}$ & $\begin{array}{l}\text { Model 3, } \\
\text { Adjusted OR } \\
\text { (95\% CI) }\end{array}$ & $\begin{array}{c}P \\
\text { Value }\end{array}$ \\
\hline 0 & 1.00 (Referent) & & 1.00 (Referent) & & 1.00 (Referent) & & 1.00 (Referent) & \\
\hline 1 & $1.23(0.89-1.71)$ & .21 & $0.94(0.66-1.33)$ & .72 & $1.09(0.75-1.58)$ & .66 & $1.10(0.75-1.61)$ & .64 \\
\hline 2 & $1.15(0.84-1.57)$ & .39 & $0.74(0.52-1.04)$ & .08 & $0.93(0.64-1.35)$ & .70 & $0.84(0.56-1.27)$ & .41 \\
\hline$\geq 3$ & $1.30(0.98-1.73)$ & .07 & $0.62(0.45-0.87)$ & .005 & $0.83(0.57-1.22)$ & .35 & $0.68(0.44-1.03)$ & .07 \\
\hline
\end{tabular}

Analyses are limited to women with no history of bilateral mastectomy or prior abnormal mammogram $(\mathrm{n}=1859)$. All models included clinic as a random effect.

*Adjusted for total visit count in past 5 years only.

${ }^{\dagger}$ Adjusted for age, marital status, ethnicity, body mass index classification, occupation, history of alcohol use, history of smoking, insurance status, length of contact with clinic, and total number of visits in past 5 years.

${ }^{\ddagger}$ Adjusted for age, marital status, ethnicity, body mass index classification, occupation, history of alcohol use, history of smoking, insurance status, length of contact with clinic, total number of visits in past 5 years; limited to women with no digestive disease (n $=$ 1379).

disorders were more likely to be up to date (adjusted OR, 1.88; 95\% CI, 1.40-2.52) (Table 7). In an unadjusted analysis, men with low back pain were more likely to be up to date; however, no association was observed in the adjusted analysis. Female patients with depression or anxiety were significantly less likely to be up to date for colorectal cancer screening (ad- justed OR, 0.71; 95\% CI, 0.56-0.91), and patients with chronic digestive disorders were more likely to be up to date (adjusted OR, 1.72; 95\% CI, 1.34-2.19) (Table 7). As with the male patients, an unadjusted analysis found that women with low back pain were more likely to be up to date; however, no association was observed in the adjusted analysis.

Table 3. Unadjusted and Adjusted Individual Chronic Conditions Association with Being Up to Date for Breast Cancer Screening According to US Preventive Services Task Force Guidelines

\begin{tabular}{|c|c|c|c|c|c|c|}
\hline \multirow[b]{3}{*}{ Chronic Disease } & \multicolumn{6}{|c|}{ Up-to-date Mammography Status } \\
\hline & \multicolumn{2}{|c|}{ Unadjusted Bivariate OR } & \multicolumn{2}{|c|}{$\begin{array}{c}\text { OR Adjusted for } \\
\text { Demographics and Chronic } \\
\text { Diseases* }\end{array}$} & \multicolumn{2}{|c|}{ Final Model ${ }^{\dagger}$} \\
\hline & OR $(95 \% \mathrm{CI})$ & $P$ Value & OR $(95 \% \mathrm{CI})$ & $P$ Value & OR (95\% CI) & $P$ Value \\
\hline None & 1.00 (Referent) & & 1.00 (Referent) & & 1.00 (Referent) & \\
\hline Arthritis & $1.10(0.91-1.34)$ & .33 & $0.94(0.74-1.18)$ & .58 & Dropped & \\
\hline Respiratory disease & $0.71(0.54-0.94)$ & .02 & $0.60(0.44-0.81)$ & .001 & $0.59(0.43-0.80)$ & .001 \\
\hline Cardiovascular disease & $0.71(0.56-0.91)$ & .006 & $0.71(0.54-0.94)$ & .02 & $0.71(0.54-0.94)$ & .02 \\
\hline Digestive disorders & $1.64(1.32-2.04)$ & $<.001$ & $1.33(1.04-1.70)$ & .02 & $1.31(1.03-1.66)$ & .03 \\
\hline Diabetes mellitus type 1 or 2 & $0.94(0.72-1.21)$ & .61 & $0.83(0.62-1.13)$ & .23 & Dropped & \\
\hline Depression/anxiety & $1.19(0.98-1.45)$ & .09 & $0.89(0.71-1.13)$ & .34 & Dropped & \\
\hline Hypertension & $1.06(0.87-1.27)$ & .58 & $1.11(0.88-1.40)$ & .38 & Dropped & \\
\hline Low-back pain & $1.23(0.98-1.53)$ & .07 & $0.92(0.71-1.19)$ & .51 & Dropped & \\
\hline
\end{tabular}

Analysis limited to women with no history of bilateral mastectomy or prior abnormal mammogram (n = 1859). All models included clinic as a random effect.

*Adjusted for age, marital status, ethnicity, body mass index classification, occupation, history of alcohol use, history of smoking, insurance status, length of contact with clinic, total number of visits in past 5 years, and the rest of the chronic diseases.

${ }^{\dagger}$ Adjusted for age, marital status, body mass index classification, history of alcohol use, history of smoking, insurance status, length of contact with clinic, total number of visits in past 5 years, asthma, cardiovascular disease, and digestive disorders. 
Table 4. Unadjusted and Adjusted Odds Ratios for Up-to-Date Cervical Cancer Screening Status According to US Preventive Services Task Force Guidelines by Number of Chronic Conditions

\begin{tabular}{|c|c|c|c|c|c|c|c|c|}
\hline \multirow[b]{3}{*}{$\begin{array}{l}\text { Number of } \\
\text { Conditions }\end{array}$} & \multicolumn{8}{|c|}{ Up-to-Date for Cervical Cancer Screening } \\
\hline & \multicolumn{6}{|c|}{ All Chronic Conditions } & \multicolumn{2}{|c|}{$\begin{array}{l}\text { Excluding Patients with } \\
\text { Digestive Disorders }\end{array}$} \\
\hline & $\begin{array}{l}\text { Bivariate OR } \\
\quad(95 \% \mathrm{CI})\end{array}$ & $\begin{array}{c}P \\
\text { Value }\end{array}$ & $\begin{array}{l}\text { Model 1,* } \\
\text { Adjusted OR } \\
\text { (95\% CI) }\end{array}$ & $\begin{array}{c}P \\
\text { Value }\end{array}$ & $\begin{array}{l}\text { Model 2, }{ }^{\dagger} \\
\text { Adjusted OR } \\
\text { (95\% CI) }\end{array}$ & $\begin{array}{c}P \\
\text { Value }\end{array}$ & $\begin{array}{l}\text { Model 3, } \\
\text { Adjusted OR } \\
\text { (95\% CI) }\end{array}$ & $\begin{array}{c}P \\
\text { Value }\end{array}$ \\
\hline 0 & 1.00 (Referent) & & 1.00 (Referent) & & 1.00 (Referent) & & 1.00 (Referent) & \\
\hline 1 & $1.05(0.68-1.63)$ & .81 & $0.79(0.49-1.26)$ & .32 & $0.75(0.44-1.27)$ & .28 & $0.79(0.46-1.36)$ & .40 \\
\hline 2 & $0.89(0.57-1.40)$ & .62 & $0.58(0.36-0.95)$ & .03 & $0.55(0.31-0.95)$ & .03 & $0.56(0.30-1.03)$ & .06 \\
\hline$\geq 3$ & $0.94(0.63-1.40)$ & .75 & $0.42(0.26-0.68)$ & $<.001$ & $0.38(0.21-0.68)$ & .001 & $0.36(0.19-0.69)$ & .002 \\
\hline
\end{tabular}

Analysis limited to women $<65$ years old with no history of hysterectomy $(\mathrm{n}=740)$. All models included clinic as a random effect. *Adjusted for total visit count in past 5 years only.

${ }^{\dagger}$ Adjusted for age, marital status, ethnicity, body mass index (BMI) class, occupation, history of alcohol use, history of smoking, insurance status, length of contact with clinic, total number of visits in past 5 years.

${ }^{\ddagger}$ Adjusted for age, marital status, ethnicity, BMI class, occupation, history of alcohol use, history of smoking, insurance status, length of contact with clinic, total number of visits in past 5 years; limited to women with no digestive disease $(\mathrm{n}=582)$.

\section{Discussion}

In general, we found that an increase in the number of chronic conditions was associated with decreased screening rates, which is what we hypothesized and has been reported elsewhere..$^{25,39}$ The magnitude and statistical significance of this effect was most pronounced for cervical cancer screening, which surprised us; we hypothesized that all cancer screening tests would be affected similarly. In addition, we were surprised to find that certain chronic diseases have more of an effect on up-to-date screening status than others for different cancers. Of the 7 types of chronic disease associated with up-to-date status, all but one was associated with decreased odds of being up to date. One category of chronic disease, digestive disorders, was associated with increased odds of being up to date for breast cancer screening and for colorectal cancer screening. The specific reasons for these associations cannot be determined from this study, but a number of pos-

Table 5. Individual Chronic Disease's Effects on Being Up to Date for Cervical Cancer Screening According to US Preventive Services Task Force Guidelines

\begin{tabular}{|c|c|c|c|c|c|c|}
\hline \multirow[b]{2}{*}{ Chronic Diseases } & \multicolumn{6}{|c|}{ Up-to-Date Cervical Cancer Screening Status } \\
\hline & $\begin{array}{c}\text { Unadjusted } \\
\text { Bivariate OR } \\
(95 \% \mathrm{CI})\end{array}$ & $\begin{array}{c}P \\
\text { Value }\end{array}$ & $\begin{array}{l}\text { Adjusted OR (95\% CI) for } \\
\text { Demographics and } \\
\text { Chronic Diseases* }\end{array}$ & $\begin{array}{c}P \\
\text { Value }\end{array}$ & $\begin{array}{l}\text { Final Model, } \uparrow \\
\text { OR (95\% CI) }\end{array}$ & $\begin{array}{c}P \\
\text { Value }\end{array}$ \\
\hline None & 1.00 (Referent) & & 1.00 (Referent) & & 1.00 (Referent) & \\
\hline Arthritis & $0.84(0.60-1.18)$ & .32 & $0.69(0.46-1.03)$ & .07 & $0.66(0.45-0.97)$ & .04 \\
\hline Asthma & $1.06(0.65-1.70)$ & .82 & $0.90(0.50-1.59)$ & .71 & Dropped & \\
\hline Cardiovascular disease & $0.71(0.43-1.19)$ & .19 & $0.59(0.32-1.08)$ & .09 & Dropped & \\
\hline Digestive disorders & $1.04(0.73-1.49)$ & .81 & $0.70(0.45-1.07)$ & .10 & Dropped & \\
\hline Diabetes mellitus type 1 or 2 & $0.70(0.47-1.07)$ & .10 & $0.69(0.39-1.20)$ & .19 & $0.60(0.36-0.98)$ & .04 \\
\hline Depression/anxiety & $1.24(0.90-1.70)$ & .18 & $1.07(0.72-1.58)$ & .74 & Dropped & \\
\hline Hypertension & $0.65(0.48-0.88)$ & .006 & $0.57(0.39-0.84)$ & .004 & $0.53(0.37-0.76)$ & .001 \\
\hline Low-back pain & $1.05(0.73-1.50)$ & .80 & $0.72(0.47-1.12)$ & .15 & Dropped & \\
\hline
\end{tabular}

Analysis limited to women less than 65 years old with no history of hysterectomy, $\mathrm{n}=740$. All models included clinic as a random effect.

*Adjusted for age, marital status, ethnicity, body mass index classification, occupation, history of alcohol use, history of smoking, insurance status, length of contact with clinic, total number of visits in past 5 years, and the other chronic diseases.

${ }^{\dagger}$ Adjusted for marital status, body mass index classification, total number of visits in past 5 years, asthma, cardiovascular disease, and digestive disorders. 
Table 6. Unadjusted and Adjusted Odds Ratios for Up-to-Date Colorectal Cancer Screening Status According to US Preventive Services Task Force Guidelines by Number of Chronic Conditions

\begin{tabular}{|c|c|c|c|c|c|c|c|c|}
\hline \multirow[b]{3}{*}{ Conditions (n) } & \multicolumn{8}{|c|}{ Up-to-Date for Colorectal Cancer Screening } \\
\hline & \multicolumn{6}{|c|}{ All Chronic Conditions } & \multicolumn{2}{|c|}{$\begin{array}{c}\text { Excluding Patients with } \\
\text { Digestive Disorders }\end{array}$} \\
\hline & $\begin{array}{l}\text { Bivariate OR } \\
(95 \% \mathrm{CI})\end{array}$ & $\begin{array}{c}P \\
\text { Value }\end{array}$ & $\begin{array}{l}\text { Model 1,* } \\
\text { Adjusted OR } \\
(95 \% \text { CI })\end{array}$ & $\begin{array}{c}P \\
\text { Value }\end{array}$ & $\begin{array}{c}\text { Model 2, } \\
\text { Adjusted OR } \\
(95 \% \text { CI })\end{array}$ & $\begin{array}{c}P \\
\text { Value }\end{array}$ & $\begin{array}{c}\text { Model 3, } \\
\text { Adjusted OR } \\
(95 \% \text { CI })\end{array}$ & $\begin{array}{c}P \\
\text { Value }\end{array}$ \\
\hline \multicolumn{9}{|l|}{$\operatorname{Men}(\mathrm{n}=1563)$} \\
\hline 0 & 1.00 (Referent) & & 1.00 (Referent) & & 1.00 (Referent) & & 1.00 (Referent) & \\
\hline 1 & $1.07(0.73-1.56)$ & .75 & $0.72(0.47-1.10)$ & .125 & $0.75(0.48-1.18)$ & .21 & $0.66(0.41-1.05)$ & .08 \\
\hline 2 & $1.34(0.93-1.93)$ & .11 & $0.73(0.48-1.09)$ & .124 & $0.84(0.53-1.31)$ & .43 & $0.74(0.46-1.20)$ & .22 \\
\hline$\geq 3$ & $1.44(1.03-2.02)$ & .03 & $0.61(0.41-0.91)$ & .016 & $0.75(0.47-1.17)$ & .20 & $0.54(0.33-0.89)$ & .02 \\
\hline \multicolumn{9}{|c|}{ Women $(\mathrm{n}=1870)$} \\
\hline 0 & 1.00 (Referent) & & 1.00 (Referent) & & 1.00 (Referent) & & 1.00 (Referent) & \\
\hline 1 & $1.11(0.79-1.56)$ & .56 & $0.81(0.57-1.17)$ & .27 & $0.86(0.58-1.26)$ & .43 & $0.82(0.54-1.23)$ & .33 \\
\hline 2 & $0.94(0.67-1.31)$ & .70 & $0.58(0.40-0.83)$ & .003 & $0.64(0.43-0.95)$ & .03 & $0.65(0.42-0.99)$ & .05 \\
\hline$\geq 3$ & $1.37(1.02-1.84)$ & .04 & $0.62(0.44-0.89)$ & .008 & $0.69(0.46-1.02)$ & .06 & $0.60(0.38-0.94)$ & .03 \\
\hline
\end{tabular}

*Adjusted for total number of visits in past 5 years only. All models included clinic as a random effect.

${ }^{\dagger}$ Adjusted for age, marital status, ethnicity, body mass index classification, occupation, history of alcohol use, history of smoking, insurance status, length of contact with clinic, and total number of visits in past 5 years.

${ }^{\ddagger}$ Adjusted for age, marital status, ethnicity, body mass index classification, occupation, history of alcohol use, history of smoking, insurance status, length of contact with clinic, total number of visits in past 5 years; limited to patients with no digestive disorders (men: $\mathrm{n}=1232$; women: $\mathrm{n}=1385$ ).

sibilities can be considered. It may be that constipation, diarrhea, or other types of digestive disorders resulted in a referral for colonoscopy, resulting in these patients being more likely to be up to date for colorectal cancer screening. Perhaps this triggered an additional referral for mammography because women needed to go to the hospital for the one test and were subsequently more likely to get the other.

For cervical cancer screening, we found arthritis/musculoskeletal disease/degenerative joint disease, diabetes mellitus, and hypertension each to be associated with lower likelihood of being up to date for Papanicolaou. This may be because Papanicolaou tests are in-office procedures, which would compete for time with other health priorities during a clinic visit. Also, women with arthritis might experience pain and movement difficulties for the Papanicolaou procedure, reducing the likelihood that they will be done. The lower ORs persisted after our adjustments for length of contact and number of clinic visits, which suggests that the type of health care visit (health maintenance visits) is more important than the number of health care visits.

The likelihood of being up to date for colorectal cancer screening was lower among men, but not among women, with cardiovascular disease. In women, we found diabetes and depression/anxiety to be associated with a lower likelihood of being up to date for colorectal cancer screening. For both men and women, having a chronic digestive disorder increased the likelihood of being up to date. Past studies showed that having heart disease is associated with lower rates of colorectal cancer screening. ${ }^{31}$ Because men generally have higher rates of heart disease, we postulate that physicians spend more time counseling and managing heart disease among men than women. Fitting cancer screening, as opportunistic events, into brief health care visits may be more difficult when the visits are for conditions that require alterations in medication management, as occurs with cardiovascular disease, diabetes, and anxiety/depression. Also, colonoscopy, whether used as a primary screening tool or as a follow-up to an abnormal less-invasive test, is perceived to carry greater risk for those with certain chronic diseases. This could affect provider and patient willingness to screen these populations. On the other hand, our finding that patients with a digestive disorder are more likely to be up to date, especially with colonoscopy, may be because colonoscopy is used both as a screening test and a diagnostic test to rule out any 
Table 7. Unadjusted and Adjusted Individual Chronic Condition's Effect on Being Up to Date for Colorectal Cancer Screening According to US Preventive Services Task Force Guidelines

\begin{tabular}{|c|c|c|c|c|c|c|}
\hline \multirow[b]{2}{*}{ Conditions } & \multicolumn{6}{|c|}{ Up-to-date Colorectal Cancer Screening Status } \\
\hline & $\begin{array}{l}\text { Unadjusted Bivariate } \\
\text { OR }(95 \% \text { CI })\end{array}$ & $P$ Value & $\begin{array}{c}\text { Demographics and Chronic } \\
\text { Diseases, Adjusted OR } \\
(95 \% \text { CI })^{*}\end{array}$ & $P$ Value & $\begin{array}{l}\text { Final Model, OR } \\
\qquad(95 \% \mathrm{CI})^{\dagger}\end{array}$ & $P$ Value \\
\hline \multicolumn{7}{|l|}{$\operatorname{Men}(\mathrm{n}=1563)$} \\
\hline No disease & 1.0 (Referent) & & 1.0 (Referent) & & 1.0 (Referent) & \\
\hline Arthritis & $1.25(0.99-1.58)$ & .07 & $0.97(0.74-1.27)$ & .82 & Dropped & \\
\hline Asthma & $1.12(0.80-1.57)$ & .51 & $1.01(0.69-1.48)$ & .96 & Dropped & \\
\hline Cardiovascular disease & $0.77(0.60-0.98)$ & .04 & $0.59(0.44-0.80)$ & $<.001$ & $0.59(0.44-0.79)$ & $<.001$ \\
\hline Digestive disorders & $2.07(1.60-2.69)$ & $<.001$ & $1.88(1.40-2.52)$ & $<.001$ & $1.83(1.37-2.44)$ & $<.001$ \\
\hline Diabetes mellitus type 1 or 2 & $0.88(0.66-1.17)$ & .37 & $0.77(0.55-1.07)$ & .12 & Dropped & \\
\hline Depression/anxiety & $1.24(0.87-1.49)$ & .36 & $0.90(0.65-1.23)$ & .51 & Dropped & \\
\hline Hypertension & $1.18(0.95-1.47)$ & .14 & $1.06(0.81-1.38)$ & .68 & Dropped & \\
\hline Low-back pain & $1.29(1.01-1.66)$ & .04 & $1.00(0.75-1.32)$ & .98 & Dropped & \\
\hline \multicolumn{7}{|l|}{ Women $(\mathrm{n}=1870)$} \\
\hline No disease & 1.0 (Referent) & & 1.0 (Referent) & & 1.0 (Referent) & \\
\hline Arthritis & $1.18(0.96-1.45)$ & .11 & $0.83(0.65-1.06)$ & .13 & Dropped & \\
\hline Asthma & $1.24(0.93-1.65)$ & .14 & $1.04(0.76-1.43)$ & .80 & Dropped & \\
\hline Cardiovascular disease & $1.08(0.85-1.38)$ & .54 & $0.94(0.71-1.26)$ & .69 & Dropped & \\
\hline Digestive disorders & $2.21(1.77-2.75)$ & $<.001$ & $1.72(1.34-2.19)$ & $<.001$ & $1.69(1.33-2.15)$ & $<.001$ \\
\hline Diabetes mellitus type 1 or 2 & $0.89(0.67-1.17)$ & .40 & $0.77(0.56-1.06)$ & .12 & $0.74(0.54-1.01)$ & .06 \\
\hline Depression/anxiety & $1.02(0.83-1.26)$ & .84 & $0.71(0.56-0.91)$ & .006 & $0.69(0.54-0.87)$ & .002 \\
\hline Hypertension & $1.04(0.85-1.27)$ & .70 & $0.90(0.71-1.15)$ & .40 & Dropped & \\
\hline Low-back pain & $1.70(1.36-2.13)$ & $<.001$ & $1.29(0.99-1.67)$ & .06 & Dropped & \\
\hline
\end{tabular}

*Each disease was adjusted for age, marital status, ethnicity, body mass index classification, occupation, history of alcohol use, history of smoking, insurance status, length of contact with clinic, total number of visits in past 5 years, and the rest of the chronic diseases. All models included clinic as random effect.

${ }^{\dagger}$ Men: adjusted for age, ethnicity, occupation, history of alcohol use, insurance status, length of contact with clinic, total number of visits in past 5 years, cardiovascular disease, and digestive disorders. Women: adjusted for age, marital status, ethnicity, body mass index classification, history of alcohol use, insurance status, length of contact with clinic, total number of visits in past 5 years, digestive disorders, depression, diabetes mellitus, and low-back pain.

potential areas of concern related to the large bowel.

We found it interesting that women with depression were less likely to be up to date for colorectal cancer screening but not for breast or cervical cancer screenings. Counseling for depression in primary care can be time consuming and may be a higher and more urgent priority for patients than preventive care, which might have caused a delay in addressing cancer screening needs. Colorectal screening, which requires bowel preparation and occurs outside of the primary care clinic, tends to be perceived as a more unpleasant and time-consuming experience than breast or cervical cancer screening, involving extra barriers for patients to overcome. ${ }^{8}$ These barriers may be particularly challenging for depressed patients.
In unadjusted analyses, low-back pain was significantly associated with being more likely to be up to date for colorectal cancer screening among both men and women. Low-back pain is a common diagnosis and often difficult to manage. Low-back pain is sometimes related to the presence of tumors, which might prompt conversations of colorectal cancer screening. Importantly, this finding did not persist after multivariable adjustments for patient and health care visit characteristics, suggesting that the finding is related to one or more of the covariates included in the analysis, such as patient age or BMI.

Physicians should consider the potential benefits of screening for these 3 cancers, as suggested by the US Preventive Services Task Force. ${ }^{1-3}$ However, decisions about cancer screening should weigh the benefits and harms for individual patients, rather 
than reflexively disregarding screening for those with substantial chronic disease burden. Similarly, physicians should be mindful of having conversations about cancer screening with their patients who have chronic diseases, with the goal of shared decision making about the relative benefits and harms of screening. Only one of the practices had an electronic health record in place, and it was not yet sophisticated enough to monitor preventive activities. The other clinics did not have any specific office systems in place for cancer screening. Because this study was observational rather than interventional, we did not undertake any efforts to revise practice procedures as part of our work. Clinics should also consider redesigning patient care roles and responsibilities to use staff in reminding or referring patients who are due about relevant cancer screening, lessening the burden on the provider-patient interaction.

The strengths of our study include our focus on both individual and total number of chronic diseases. Past studies often used a combined comorbidity index, such as the Charlson index,${ }^{34}$ or focused on a specific disease, such as patients with diabetes or cardiovascular disease. ${ }^{21-23,29,40}$ Our findings showed that individual chronic conditions have a varied impact on one's up-to-date status for cancer screening. Understanding why this occurs would facilitate more appropriate screenings and meeting the goals of Healthy People 2020.

Other strengths include our use of medical chart review rather than patient self-report, which suffers from social response bias and recall bias. ${ }^{41}$ By recording actual completion of screening tests rather than physician recommendations, we could obtain more accurate, objective records of if and when screening tests were done. In addition, our study included screening for 3 relatively common cancers that all have specific screening recommendations for primary care clinicians. Last, we focused this study on rural underserved and understudied patients. Because prior studies showed that access to physicians plays a significant role in receiving appropriate cancer screening, we tried to eliminate this factor by abstracting charts at primary care clinics, where patients have an established relationship. $^{40}$

Potential limitations of our study included missing patient information, such as insurance and ethnicity; in addition, we did not collect information on specific patient and physician perspectives on the impact chronic diseases can have on cancer screening. The latter would further elucidate potential barriers to screening. Missing information regarding patient characteristics and demographics could lead to information bias; however, we included in our analysis a category of "not noted" to account for any impact this category may have on screening status. We used patients with "no disease" as our referent group, which might have resulted in lower ORs than what might be found in those who are sick. However, the screening rates for those with "no disease" under the categories that we examined were low $(<50 \%)$, despite the opportunity for more preventive visits for those patients. For our cervical cancer screening analysis, we only included women between 55 to 65 years old, which precluded understanding cervical cancer screening among patients younger than age 55 . We were not able to collect information regarding patients' functional status and quality of life, which would help us further assess relationships between chronic disease and cancer screening. Another limitation is the possible lack of representativeness due to patients being from 4 rural clinics in a single state. In addition, we do not how the numbers of comorbid chronic conditions and the prevalence of chronic diseases compare with other study samples, which may indicate our level of representativeness.

In the future, it will be useful to gather information on patients' and physicians' perspectives on cancer screenings and determine how best to fit cancer screening into opportunistic visits for those with multiple chronic conditions. Real-time observations might capture discussions about the risks, benefits, and overall value of screening in patients whose life expectancy might be uncertain. Interventional studies could also be done to evaluate how best to improve screening among those patients with conditions that bear less risk of mortality, such as depression and low-back pain, as well as for those patients with multiple high-risk diseases in the context of their other health priorities.

\section{Conclusion}

We found that specific types of chronic conditions have a larger effect on being up to date for cancer screening than the total number of conditions. When the number of conditions reached 3 or more, however, they also had an impact on screening status, especially for cervical cancer screening. 
Chronic diseases that demand significant physician time in the clinic for management, such as diabetes or heart disease, seem to reduce the likelihood of being up to date for screening.

\section{References}

1. Screening for cervical cancer. Summary of recommendations and evidence. Rockville, MD: U.S. Preventive Services Task Force; 2012. Available from: http://www. uspreventiveservicestaskforce.org/uspstf11/cervcancer/ cervcancerrs.htm\#summary. Accessed July 17, 2014.

2. Screening for breast cancer. Rockville, MD: U.S. Preventive Services Task Force; 2009. Available from: http://www.uspreventiveservicestaskforce.org/ uspstf/uspsbrca.htm. Accessed July 17, 2014.

3. Screening for colorectal cancer. Rockville, MD: U.S. Preventive Services Task Force; 2008. Available from: http://www.uspreventiveservicestaskforce.org/ uspstf/uspscolo.htm. Accessed July 17, 2014.

4. US Cancer Statistics Working Group. United States cancer statistics: 1999-2010 incidence and mortality web-based report. Atlanta: U.S. Department of Health and Human Services, Centers for Disease Control and Prevention, and National Cancer Institute; 2013. Available from: http://apps.nccd.cdc.gov/ uscs/toptencancers.aspx. Accessed July 17, 2014.

5. Sasieni P, Castanon A, Cuzick J. Effectiveness of cervical screening with age: population based casecontrol study of prospectively recorded data. BMJ 2009;339:b2968.

6. Cancer trends progress report-2011/2012 update. Breast cancer screening. Bethesda, MD: National Cancer Institute, National Institutes of Health; 2010. Available from: http://progressreport.cancer.gov/doc_detail.asp?pid=1\& $\mathrm{did}=2007 \&$ chid $=72 \&$ coid $=716 \&$ mid $=$ \#benefits. Accessed July 17, 2014.

7. Cancer trends progress report-2011/2012 update. Cervical cancer screening. Bethesda, MD: National Cancer Institute, National Institutes of Health; 2010. Available from: http://progressreport.cancer.gov/doc_detail.asp? pid $=1 \& \operatorname{did}=2009 \& \operatorname{chid}=92 \&$ coid $=917 \& \operatorname{mid}=$. Accessed July 17, 2014.

8. Jones RM, Devers KJ, Kuzel AJ, Woolf SH. Patientreported barriers to colorectal cancer screening: a mixed-methods analysis. Am J Prev Med 2010;38: 508-16.

9. Smith RA, Cokkinides V, Brooks D, Saslow D, Shah M, Brawley OW. Cancer screening in the United States, 2011: a review of current American Cancer Society guidelines and issues in cancer screening. CA Cancer J Clin 2011;61:8-30.

10. Centers for Disease Control and Prevention (CDC). Cancer screening-United States, 2010. MMWR Morb Mortal Wkly Rep 2012;61:41-5.

11. South Carolina Rural Health Research Center. Rural residents lag in preventive services use; lag increases with service complexity. Policy brief no. 1.
Columbia: South Carolina Rural Health Research Center; 2009.

12. Doescher MP, Jackson JE. Trends in cervical and breast cancer screening practices among women in rural and urban areas of the United States. J Public Health Manag Pract 2009;15:200-9.

13. Coughlin SS, Thompson TD, Hall HI, Logan P, Uhler RJ. Breast and cervical carcinoma screening practices among women in rural and nonrural areas of the United States, 1998-1999. Cancer 2002;94: 2801-12.

14. Coughlin SS, Thompson TD. Colorectal cancer screening practices among men and women in rural and non-rural areas of the United States, 1999. J Rural Health 2004;20:118-24.

15. Carney PA, O’Malley J, Buckley DI, et al. Influence of health insurance coverage on breast, cervical, and colorectal cancer screening in rural primary care settings. Cancer 2012;118:6217-25.

16. Finney Rutten LJ, Nelson DE, Meissner HI. Examination of population-wide trends in barriers to cancer screening from a diffusion of innovation perspective. Prev Med 2004;38:258-68.

17. Swan J, Breen N, Coates RJ, Rimer BK, Lee NC. Progress in cancer screening practices in the United States: results from the 2000 National Health Interview Survey. Cancer 2003;97:1528-40.

18. Ruffin MT, Gorenflo DW, Woodman B. Predictors of screening for breast, cervical, colorectal and prostatic cancer among community-based primary care practices. J Am Board Fam Pract 2000;13:1-10.

19. Michels KB, Solomon CG, Hu FB, et al. Type 2 diabetes and subsequent incidence of breast cancer in the nurses' health study. Diabetes Care 2003;26: 1752-8.

20. Yuhara H, Steinmaus C, Cohen SE, Corley DA, Tei $\mathrm{Y}$, Buffler PA. Is diabetes mellitus an independent risk factor for colon cancer and rectal cancer? Am J Gastroenterol 2011;106:1911-21.

21. Larsson SC, Mantzoros CS, Wolk A. Diabetes mellitus and risk of breast cancer: a meta-analysis. Int J Cancer 2007;121:856-62.

22. Coughlin SS, Calle EE, Teras LR, Petrelli J, Thun MJ. Diabetes mellitus as a predictor of cancer mortality in a large cohort of US adults. Am J Epidemiol 2004;159:1160-7.

23. Karathanasi I, Kamposioras K, Cortinovis I, et al. Moving ahead in diabetics' cancer screening; food for thought from the hellenic experience. Eur J Cancer Care 2009;18:255-63.

24. Lipscombe LL, Hux JE, Booth GL. Reduced screening mammography among women with diabetes. Arch Intern Med 2005;165:2090-5.

25. Kiefe CI, Funkhouser E, Fouad MN, May DS. Chronic disease as a barrier to breast and cervical cancer screening. J Gen Intern Med 1998;13:357-65.

26. Ludman EJ, Ichikawa LE, Simon GE, et al. Breast and cervical cancer screening: specific effects of 
depression and obesity. Am J Prev Med 2010;38: 303-10.

27. Yasmeen S, Xing G, Morris C, Chlebowski RT, Romano PS. Comorbidities and mammography use interact to explain racial/ethnic disparities in breast cancer stage at diagnosis. Cancer 2011;117:3252-61.

28. Heflin MT, Oddone EZ, Pieper CF, Burchett BM, Cohen HJ. The effect of comorbid illness on receipt of cancer screening by older people. J Am Geriatr Soc 2002; 50:1651-8.

29. Zhao G, Ford ES, Ahluwalia IB, Li C, Mokdad AH. Prevalence and trends of receipt of cancer screenings among US women with diagnosed diabetes. J Gen Intern Med 2008;24:270-5.

30. Nutting PA, Baier M, Werner JJ, Cutter G, Conry C, Stewart L. Competing demands in the office visit: what influences mammography recommendations? J Am Board Fam Pract 2001;14:352-61.

31. Fontana S, Baumann LC, Helberg C, Love RR. The delivery of preventive services in primary care practices according to chronic disease status. Am J Public Health 1997;87:1190-6.

32. Healthy People 2020. Topics and objectives. Washington, DC: US Department of Health and Human Services; 2012. Available from: http://www.healthypeople. gov/2020/topicsobjectives2020/objectiveslist.aspx? topicId=5. Accessed July 17, 2014.

33. Charlson ME, Pompei P, Ales KL, MacKenzie CR. A new method of classifying prognostic comorbidity in longitudinal studies: development and validation. J Chronic Dis 1987;40:373-83.

34. Screening for breast cancer (2002). Rockville, MD: US Preventive Services Task Force; 2010. Available from: http://www.uspreventiveservicestaskforce.org/ uspstf/uspsbrca2002.htm. Accessed July 17, 2014.

35. Screening for cervical cancer: recommendations and rationale. Rockville, MD: Agency for Healthcare Research and Quality; 2003.

36. US Preventive Services Task Force. Screening for colorectal cancer: recommendation and rationale. Ann Intern Med. 2002;137:129-31.

37. Landis JR, Koch GG. The measurement of observer agreement for categorical data. Biometrics 1977;33: 159-74.

38. Sim J, Wright CC. The kappa statistic in reliability studies: use, interpretation, and sample size requirements. Phys Ther 2005;85:257-68.

39. Schoen RE, Marcus M, Braham RL. Factors associated with the use of screening mammography in a primary care setting. J Community Health 1994;19: 239-52.

40. Larsson SC, Orsini N, Wolk A. Diabetes mellitus and risk of colorectal cancer: a meta-analysis. J Natl Cancer Inst 2005;97:1679-87.

41. Podsakoff PM, MacKenzie SB, Lee JY, Podsakoff NP. Common method biases in behavioral research: a critical review of the literature and recommended remedies. J Appl Psychol 2003;88:879-903. 